\title{
Do tradicionalismo às novas tendências: contribuições e reflexões
}

\author{
From traditionalism to new trends: contributions and reflections \\ Del tradicionalismo a las nuevas tendencias: aportes y reflexiones
}

Recebido: 20/09/2021 | Revisado: 26/09/2021 | Aceito: 28/09/2021 | Publicado: 01/10/2021

Mônica Vieira da Silva
ORCID: https://orcid.org/0000-0003-0828-2236
Escola Estadual Conquista D’Oeste, Brasil
E-mail: monicaconq@ hotmail.com
Edione Teixeira de Carvalho
ORCID: https://orcid.org/0000-0002-1208-3961
Instituto Federal de Educação, Ciência e Tecnologia de Mato Grosso, Brasil
E-mail: edione.carvalho@ svc.ifmt.edu.br
Gisele Silva Lira de Resende
ORCID: https://orcid.org/0000-0001-9527-3543
Centro Universitario Cathedral, Brasil
E-mail: giselelira.gl@gmail.com
Miriam Vieira da Silva
ORCID: https://orcid.org/0000-0003-3097-6533
Escola Estadual Deputado Oscar Soares, Brasil
E-mail: mimineirinha_10@ hotmail.com
Vilma Rodrigues de Abreu
ORCID: https://orcid.org/0000-0003-3792-4234
Escola Estadual Conquista D’Oeste, Brasil
E-mail: vilmarodriguesabreu@gmail.com

\begin{abstract}
Resumo
A sociedade atual anseia por uma educação de qualidade e contextualizada, em que o aluno tenha autonomia e possa expressar suas ideias. O objetivo do artigo é compreender como as tendências pedagógicas brasileiras podem contribuir com um fazer pedagógico significativo, inovador e dinâmico, através de métodos que podem ser considerados ativos. Para alcançar este objetivo, nos propusemos a observar a existência dos métodos ativos em cada tendência e comparar as metodologias tradicionais com novas metodologias de ensino, buscando assim identificar quais contribuições ambas podem trazer para a aprendizagem dos alunos. Elaborado através de pesquisa bibliográfica, documental e uma pesquisa de campo, o artigo procura levar professores, gestores e toda comunidade escolar a refletirem sobre a importância da participação ativa do aluno no processo de aprendizagem, levando em consideração o processo histórico da educação no Brasil. A pesquisa teve como sujeitos 14 (quatorze) professores do Ensino Médio, lotados na Escola Estadual Conquista D'Oeste. Ao finalizar a pesquisa conclui-se que alguns professores não conhecem a trajetória da educação brasileira, ou não conhece a definição e as características de algumas tendências pedagógicas. Isso nos leva a questionar a estrutura da grade e a qualidade dos cursos de licenciatura e também a formação continuada, pois uma das temáticas mais presentes na formação atual são as metodologias ativas.
\end{abstract}

Palavras-chave: Metodologias ativas; Tendências pedagógica; Formação continuada.

\begin{abstract}
Today's society yearns for a quality and contextualized education, in which the student has autonomy and can express their ideas. The aim of the article is to understand how Brazilian pedagogical trends can contribute to a significant, innovative and dynamic pedagogical practice, through methods that can be considered active. To achieve this goal, we proposed to observe the existence of active methods in each trend and compare traditional methodologies with new teaching methodologies, thus seeking to identify which contributions both can bring to student learning. Prepared through bibliographical research, documentary and field research, the article seeks to lead teachers, administrators and the entire school community to reflect on the importance of the student's active participation in the learning process, taking into account the historical process of education in Brazil. The research had 14 (fourteen) high school teachers as subjects, working at the Conquista D'Oeste State School. At the end of the research, it is concluded that some teachers do not know the trajectory of Brazilian education, or do not know the definition and characteristics of some pedagogical trends. This leads us to question the structure of the grid and the quality of undergraduate courses and also continuing education, as one of the most present themes in current education is active methodologies.
\end{abstract}

Keywords: Active methodologies; Pedagogical trends; Continuing education. 


\begin{abstract}
Resumen
La sociedad actual anhela una educación de calidad y contextualizada, en la que el alumno tenga autonomía y pueda expresar sus ideas. El objetivo del artículo es comprender cómo las tendencias pedagógicas brasileñas pueden contribuir a una práctica pedagógica significativa, innovadora y dinámica, a través de métodos que pueden considerarse activos. Para lograr este objetivo, nos propusimos observar la existencia de métodos activos en cada tendencia y comparar las metodologías tradicionales con las nuevas metodologías de enseñanza, buscando así identificar qué aportes ambos pueden aportar al aprendizaje de los estudiantes. Elaborado a través de investigación bibliográfica, documental y de campo, el artículo busca llevar a docentes, administradores y a toda la comunidad escolar a reflexionar sobre la importancia de la participación activa del estudiante en el proceso de aprendizaje, tomando en cuenta el proceso histórico de la educación en Brasil. La investigación contó con 14 (catorce) profesores de secundaria como sujetos, que trabajaban en la Escuela Estatal Conquista D’Oeste. Al final de la investigación, se concluye que algunos docentes desconocen la trayectoria de la educación brasileña, o desconocen la definición y características de algunas tendencias pedagógicas. Esto nos lleva a cuestionar la estructura de la grilla y la calidad de los cursos de pregrado y también de la educación continua, ya que uno de los temas más presentes en la educación actual son las metodologías activas.
\end{abstract}

Palabras clave: Metodologías activas; Tendencias pedagógicas; Educación continua.

\title{
1. Introdução
}

A história da Educação formal no Brasil iniciou em 1549, com a chegada dos jesuítas às terras brasileiras, seu marco inicial se deu com o trabalho catequético dos jesuítas, que tinha caráter pedagógico, uma vez que os mesmos consideravam que as práticas pedagógicas eram importantes para o convencimento dos povos indígenas. Antes os povos indígenas que habitavam o Brasil tinham uma educação baseada em três elementos básicos: a força da tradição, a força da ação e a força do exemplo, nesse modelo educacional não havia a necessidade de elaborar formas de intervenção na prática educativa, a educação se dava através da própria prática educativa, portanto não havia ainda uma ideia pedagógica (Saviani, 2019).

O artigo tem como principais referências bibliográficas: Saviani (1987, 2019), Libâneo (2006), Luckesi (1994), Freire (19870 e Freinet (2001) que trazem sua visão particular das tendências pedagógicas brasileiras. Ele traz também diversos autores da atualidade, como Bacich (2018, 2019), Moran (1998, 2007, 2018), Camargo (2018), Daros (2018), Cavalcanti (2018) e Filatro (2018), trazem em seus livros ideias inovadoras, que podem revolucionar a sala de aula, fazer com que o aluno tenha autonomia em seu processo de aprendizagem, mesmo sem nenhuma tecnologia a disposição.

Elaborado através de pesquisa bibliográfica, documental e uma pesquisa de campo, esta investigação científica busca provocar, junto aos professores, gestores e toda comunidade escolar uma reflexão acerca da importância da participação ativa do aluno no processo de aprendizagem, levando em consideração o processo histórico da educação no Brasil.

Conhecer essas tendências pedagógicas e entender como cada uma delas influenciaram e influenciam os professores, se faz necessário, pois é através do conhecimento histórico que podemos fazer uma análise do presente e tentar projetar um futuro com uma educação de qualidade.

O objetivo do artigo é compreender como as tendências pedagógicas brasileiras podem contribuir com um fazer pedagógico significativo, inovador e dinâmico, através de métodos que podem ser considerados ativos. Para alcançar este objetivo, nos propusemos a observar a existência dos métodos ativos em cada tendência e comparar as metodologias tradicionais com novas metodologias de ensino, buscando assim identificar quais contribuições ambas podem trazer para a aprendizagem dos alunos.

\section{Metodologia}

A pesquisa está estruturada em dados científicos que buscam provar a importância de se conhecer as tendências pedagógicas diante da inserção das metodologias ativas nas escolas. Segundo Andrade (1999. p 124) "Formular o problema não se limita a identificá-lo; é preciso defini-lo, circunscrever seus limites, isolar e compreender seus fatores peculiares, ou seja, indicar as variáveis que sobre ele intervêm e as possíveis relações entre elas". 
A metodologia utilizada na elaboração deste trabalho foi uma pesquisa bibliográfica, utilizando a análise documental e pesquisa de campo. A análise documental foi realizada em documentos como o Projeto Político Pedagógico e nos planos de aulas dos professores da escola. A pesquisa campo se deu in loco e através do Google Forms, com os professores da Escola Estadual Conquista D’Oeste localizada na rua das Jabuticabeiras, número 1339, centro, no município de Conquista D’OesteMT.

Gil (2008), caracteriza a pesquisa bibliográfica como a leitura, a análise e a interpretação de material impresso. Exemplo: livros, imagens, manuscritos, documentos mimeografados ou fotocopiados, periódicos, mapas, entre outros.

A análise documental de acordo com Gil (2008) é muito parecida com a bibliográfica. A diferença está na natureza das fontes, pois esta forma vale-se de materiais que não receberam ainda um tratamento analítico, ou que ainda podem ser reelaborados de acordo com os objetos da pesquisa. Além de analisar os documentos de "primeira mão" (documentos de arquivos, igrejas, sindicatos, instituições etc.), existem também aqueles que já foram processados, mas podem receber outras interpretações, como relatórios de empresas, tabelas etc.

Segundo Gonsalves (2001, p.67), “A pesquisa de campo é o tipo de pesquisa que pretende buscar a informação diretamente com a população pesquisada. Ela exige do pesquisador um encontro mais direto. Nesse caso, o pesquisador precisa ir ao espaço onde o fenômeno ocorre, ou ocorreu e reunir um conjunto de informações a serem documentadas [...]".

A pesquisa tem caráter qualitativo, visto que Rocha \& Deusdará (2005) afirmam que o objetivo da pesquisa qualitativa é captar um saber que está por trás da superfície textual. Assim, o pesquisador deve ser um espião da ordem que se propõe a desvendar a subversão escondida; deve ser um leitor privilegiado por dispor de técnicas seguras de trabalho.

Os dados foram coletados através de um questionamento aplicado pelo Google Formulário. E os sujeitos que compõem a amostra são 14 professores que atuam no Ensino Médio da Escola Estadual Conquista D’Oeste. Vale a pena ressaltar que a escola possui o Ensino Médio nas modalidades: Regular, Educação de Jovens e Adultos. As observações de aulas para comprovar a metodologia de ensino utilizada pelo professor, devido a pandemia se deram através do Google Meet.

A análise de dados se deu através da triangulação de dados coletados na observação, no questionário e nas bibliografias voltadas à temática. Denzin (2006) caracteriza a triangulação como uma estratégia de validação à pesquisa. Segundo Minayo (2005) triangular é combinar e cruzar múltiplos pontos de vista, levando em consideração a visão de vários informantes e empregando uma variedade de técnicas de coleta de dados.

\section{Fundamentação Teórica}

Para compreendermos melhor onde, como surgiu e quem foram os principais teóricos que disseminaram o método de ensino baseado no aluno como ator principal no processo de aprendizagem, o que chamamos de aluno ativo, precisamos fazer uma linha cronológica das principais tendências pedagógicas que fizeram parte da educação no Brasil, pois foi através dessas tendências filosóficas que os professores construíram e ainda constroem sua identidade profissional.

A Figura 1 apresenta como estão divididas as tendências pedagógicas brasileiras de acordo com Libâneo.

Figura 1 - Esquema de Divisão das Tendências Pedagógicas Brasileiras.

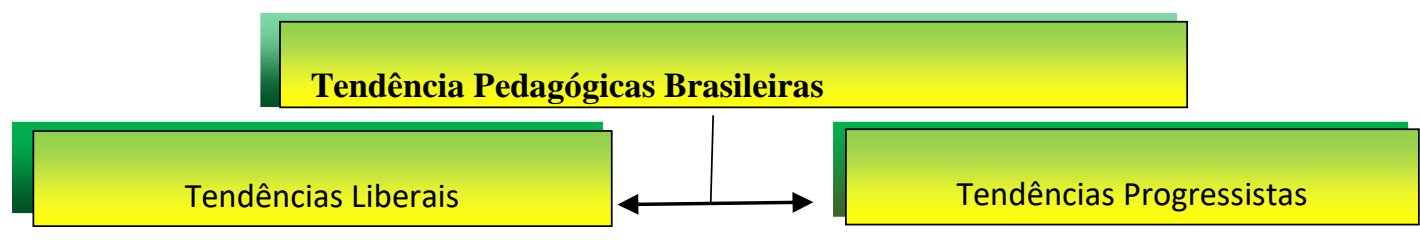

Fonte: Libâneo (2006), autores (2021). 
A denominação Tendências Liberais não diz propriamente o que condiz a tendência pedagógica, "Liberal" nesse caso não está relacionado à escolha, à democracia em si. Ela tem a função de preparar indivíduos para desempenhar papéis sociais, de acordo com as aptidões individuais de cada um, adaptando-se às normas sociais vigentes e as culturais (Libâneo, 2006). Luckesi (1994), acredita que esta norma cultural está ligada à aceitação de diferença de classes sociais existentes na sociedade. De acordo com Libâneo (2006), a tendência liberal está dividida em quatro etapas de acordo com a Figura 2.

Figura 2 - Esquema de Divisão da Tendência Liberal.

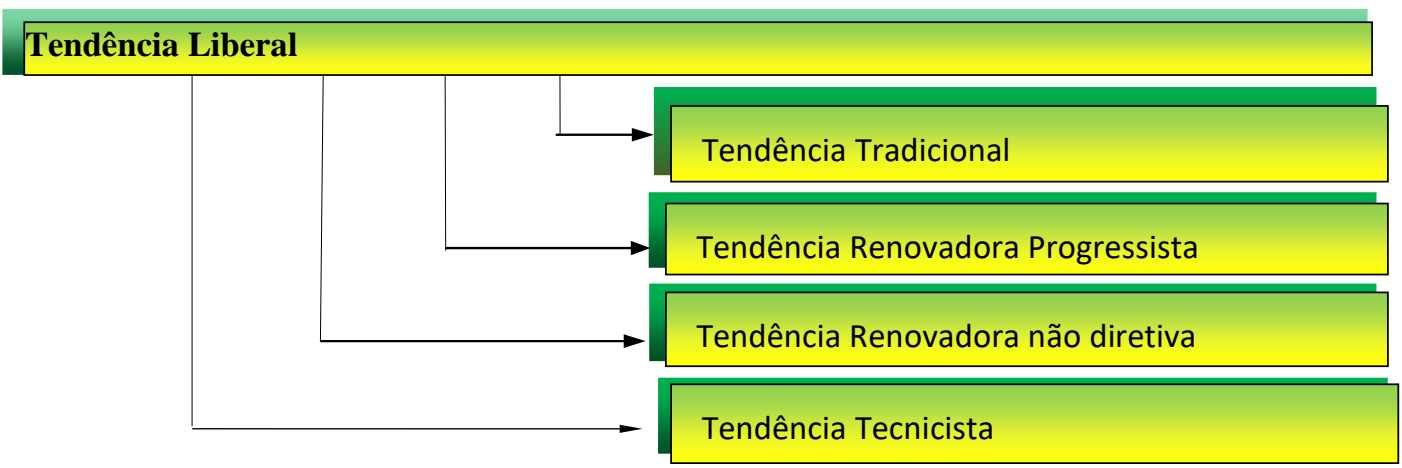

Fonte: Libâneo (2006), autores (2021).

Tendência Liberal Tradicional (1549- 1920) - Essa tendência teve início em 1549 com a chegada dos jesuítas ao Brasil e vai até cerca 1920. Seu objetivo principal era preparar o aluno para a sociedade, o conhecimento era considerado uma verdade absoluta e eram repassados ao longo dos anos, as aulas tinham como método principal a demonstração verbal, com técnicas mecânicas e de repetição. Considerava o professor como centro do processo de aprendizagem, alguém que continha o conhecimento e este era incontestável.

Saviani (2019) enfatiza que esta tendência era dominada pelos interesses políticos e econômicos. Libâneo (2006), caracteriza a tendência tradicional pelo ensino humanístico, onde o aluno era educado para atingir sua plena realização através do próprio esforço. Nessa tendência o professor é o único ser ativo e os conteúdos não são voltados à realidade do aluno.

Confirma-se, portanto, que essa tendência tradicional não apresenta traços de metodologias ativas. O professor era o detentor de todo conhecimento, o aluno era um simples ouvinte, não era levado em consideração suas individualidades, seu ritmo de aprendizagem, o ensino era mecânico e repetitivo, com uma educação voltada a atender os anseios da corte.

Tendência Liberal Renovadora Progressista (1917 - 1920/30) - Para Di Giorge (1992), John Dewey, William Heard Kilpatrick, Ellen Parkhurst, Pavel Blonsky, Ovídio Decroly e Maria Montessori foram grandes pensadores que defendiam as ideias da Escola Nova. O autor ainda afirma que provavelmente John Dewey foi o mais importante disseminador da Escola Nova. "O ideal educacional de Dewey era de que a educação se desse, o máximo possível, junto com a própria vida: quanto mais se integrassem atividade escolar e as demais atividades cotidianas, melhor.” (Di Giorgi, 1992, p.37).

A Tendência Liberal Renovadora Progressista tinha como principal característica o ativismo do aluno, considerando-o um ser curioso e valorizando o aprender fazendo, a pesquisa, a descoberta, o estudo da natureza e do social como um todo, nesse caso o professor tem um papel de facilitador. Os métodos de ensino nessa tendência já eram baseados no aluno ativo. Luzuriaga (1980), afirma que a Escola Nova veio para mudar a forma de ensino, antes intelectualista e livresca, dando sentido vivo e ativo, por isso o autor à chamou também de Escola Ativa. 
Todo esse contexto nos leva a refletir sobre o "porque" até hoje temos tantos professores que ainda utilizam metodologias tradicionais, colocando o professor como detentor do conhecimento e um ser autoritário, se a um século o método ativo já vinha sendo analisado.

Tendência Liberal Renovadora não diretiva ou Escola Nova - A Escola Nova teve como pioneiro Anísio Teixeira, que juntamente com Fernando Azevedo e Lourenço Filho, idealizaram uma escola inovadora. Juntos, os três e mais 23 signatários escreveram e divulgaram um dos documentos mais importantes da história pedagógica do Brasil, o "Manifesto dos Pioneiros da Educação Nova". Baseado nos princípios da laicidade, gratuidade, obrigatoriedade e coeducação, o documento previa autonomia na função educacional, o que evitaria a interferência de interesses políticos. O documento também menciona as bases psicológicas da educação, com ideias respaldadas no conhecimento científico, estimulando o esforço do educando e preparando para a vida social. O manifesto também trazia a nova estrutura do sistema educacional: escola infantil ou préprimária para alunos de 4 a 6 anos, escola primária para alunos entre 7 a 12 anos e escola secundária que era voltada para alunos de 12 a 18 anos de idade (Saviani, 2019).

Saviani (2019) enfatiza que as principais influências para elaboração do Manifesto vieram principalmente de Durkheim, Pareto, Dewey e Fichte. Libâneo (2006) faz um resumo dessa tendência pedagógica. Segundo o autor, além do pedagógico, ela leva em consideração o psicológico, e a escola tem uma função primordial a formação de atitude. O professor atua como um facilitador no processo de aprendizagem, os conteúdos passam para segundo plano, focando na busca de autoconhecimento do aluno.

Observa-se, portanto, que a Tendência Liberal Renovadora não diretiva ou Escola Nova, também trazia como autor principal do processo de aprendizagem o aluno, e tinha como foco a formação de atitudes voltadas para a democracia. Fica claro também que apesar de idealizarem um novo formato para a educação, ele não foi colocado em prática em todas as unidades de ensino, ora pela resistência de alguns professores, ora por falta de suporte do governo.

Tendência Liberal Tecnicista - Presente no Brasil nas décadas de 1960, 1970 e 1980, com um espírito patriota elevando o lema da bandeira brasileira, "Ordem e Progresso", a tendência tecnicista visava preparar mão de obra para empresas oriundas principalmente dos Estados Unidos da América. Com uma ideia de produtividade voltada para o taylorismo e o fordismo.

Libâneo (2006, p. 28) afirma que a Tendência Liberal Tecnicista funciona como "[...] modeladora do comportamento humano, através de técnicas especificas", com a função especifica de preparar o indivíduo para atuar no mercado de trabalho, com habilidades especificas para sua função. Os conteúdos eram apenas científicos, eliminando qualquer vestígio de subjetividade, com o professor administrando o processo de ensino e o aluno volta a ser apenas um receptor de conteúdos geralmente aplicados através de livros e manuais.

Luckesi (1994, p. 55-56) acrescenta, "A tendência liberal tecnicista subordina a educação à sociedade, tendo como função a preparação de "recursos humanos" (mão-de-obra para a indústria)". Observa-se que essa tendência não se preocupava em formar cidadãos críticos, se baseava apenas na preparação do indivíduo para o trabalho, tinha uma visão capitalista da educação.

Ainda segundo Saviani (2019), nessa tendência educacional a eficiência e a eficácia sem dúvida eram as palavras de ordem. $\mathrm{O}$ ensino era baseado em técnicas repetitivas, e tinha como objetivo aperfeiçoar a ordem social, o aluno apenas reproduzia, um depósito de conhecimento e o professor, refém da técnica, era o ser que depositava esses conhecimentos.

Libâneo (2006), apresenta os principais autores e defensores da tendência tecnicista, destacando Skinner, Gagné, Bloon e Mager. Essa tendência tem como referência a Lei 5.540/68 que fixava normas de organização e funcionamento do 
ensino superior e sua articulação com a escola média, e a Lei 5.692/71, que fixava Diretrizes e Bases para o ensino de $1^{\circ}$ e $2^{\circ}$ graus, e dava outras providências. Essa lei foi revogada em 1996, com a instituição da LDB 9394/96.

No entanto, não podemos negar que o tecnicismo enquanto viés pedagógico teve e tem sua merecida importância no contexto educacional, pois contribuiu de forma significativa para a inovação tecnológica, no entanto ela não atende os anseios da atual sociedade multicultural, que enfatiza a importância de uma aprendizagem ativa, que contribua na formação de cidadãos críticos e com capacidade de tomarem decisões de forma individual e coletiva.

Enquanto no Brasil as tendências liberais iam ganhando espaço, exilado, Paulo Freire escrevia suas maiores obras. Freire (1921-1997) é considerado o precursor da abordagem progressista no Brasil, o autor coloca o homem como sujeito principal da educação. As tendências progressistas são opostas às tendências liberais, tem o aluno com um ser em construção, ela se distancia do ensino mecânico/repetitivo e parte de uma análise crítica social. A figura abaixo representa como está dividida a Tendência Progressista.

De acordo com Libâneo (2006), a Tendência Progressista está dividida em quatro etapas de acordo com a Figura 3

Figura 3 - Esquema de Divisão da Tendência Progressista.

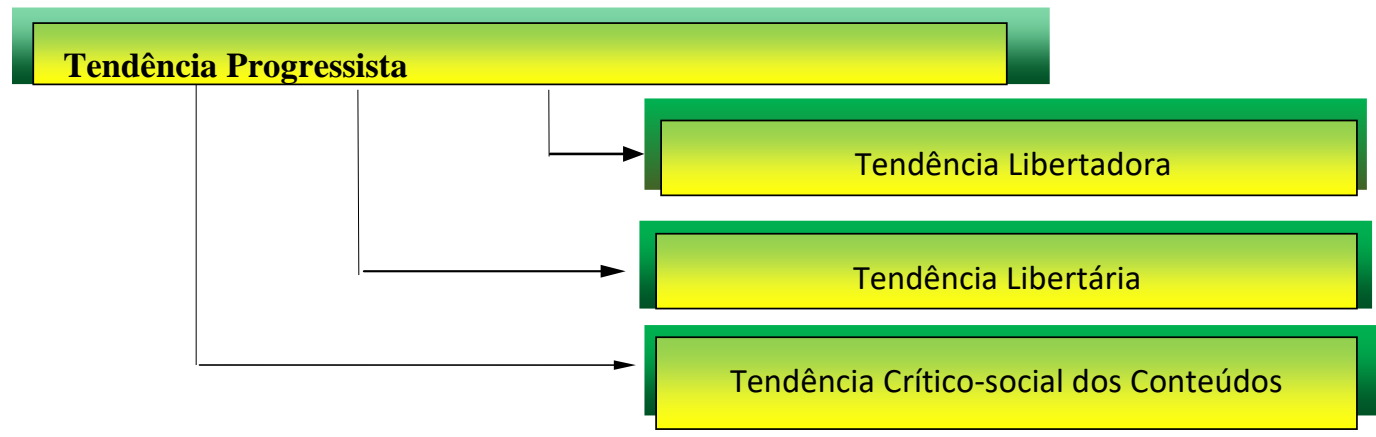

Fonte: Libâneo (2006), autores (2021).

Tendência Libertadora - O grande nome dessa tendência educacional foi sem dúvida Paulo Freire, uma corrente progressista que veio de uma pedagogia da "educação popular" que ansiava uma educação "do povo pelo povo, para o povo e com o povo" (Saviani, 2019, p. 415). Para Freire (1987) o homem é um ser inacabado, em construção, um ser capaz de se transformar ao longo de sua existência, e a ignorância humana é que faz com que sejamos oprimidos. Ele considera a educação como algo libertador, pois somente tornando-se seres críticos e capazes de se posicionarem de forma consciente é que poderemos atuar na sociedade.

Freire (1987) defendia a ideia de uma educação problematizadora e não uma educação bancária, onde "o educador vai "enchendo" os educandos de falso saber, que são os conteúdos impostos" (p. 45), enquanto que na educação problematizadora os educandos desenvolvem por si o poder de compreender, de captar informações ao seu redor que lhes dão a oportunidade de compreensão e atuação no mundo.

$\mathrm{Na}$ tendência libertadora a escola tinha como papel principal transformar a consciência da realidade, os conteúdos eram aplicados através de temas geradores, através de codificação, decodificação e problematização em situações reais, e tanto o professor quanto os alunos eram considerados sujeitos do conhecimento.

A tendência libertadora exerce muita influência sobre os educadores brasileiros, pois foi idealizada por um educador que viveu no Brasil, que conhece a nossa realidade, nosso contexto educacional. Essa influência é ainda maior quando se trata 
de professores que atuam na alfabetização, seja ela de jovens e adultos ou não. Ao relacionar situações problemas com o cotidiano do aluno, o educador está dando significado ao conteúdo, está fazendo com que o aluno aprenda ativamente no meio em que vive, e isso está diretamente relacionado as metodologias ativas.

Tendência Libertária - Após o regime militar, a tendência libertária surge como uma forma de democracia, e tem como adeptos pensadores exilados durante o regime militar que acabavam de retornar ao país. Fundamentada na busca por uma educação inclusiva e de qualidade para todos, idealizados por uma escola democrática e uma intensa participação em movimentos sociais, em sua visão a educação ultrapassa os muros da escola, assim como traz para dentro dela um censo democrático, buscando formalizar os conselhos escolares, os grêmios estudantis e a gestão democrática na escolha de diretores.

Um dos principais influenciadores dessa tendência no Brasil, foi Celestin Freinet, fomentada com chegada de Michel Launay e de Janira Brasilino de Souza ao Brasil. Com sua crítica à escola tradicional e à subordinação do sistema educacional à elite, Freinet idealizou uma escola sem muros, onde a criança e a comunidade interagem de forma a produzir conhecimento (Freinet, 2001). Nesta perspectiva o papel da escola está' em promover a coletividade e lutar contra o sistema repressor do estado, para isso se propõe a ministrar conteúdos que focam em atender as necessidades sociais dos alunos, tendo no professor uma figura de orientador e pertencente a esse grupo comunitário, e no aluno um ser autônomo, capaz de interagir com a sociedade e produzir conhecimento, sendo um ser ativo na sociedade.

Tendência Crítico-social dos Conteúdos ou Histórico-Crítica - Uma proposta formulada por Demerval Saviani, e defendida por José Carlos Libâneo, a Tendência Crítico-social dos conteúdos ou Histórico-Crítica foi apresentada no livro Democratização da escola pública, publicado em 1985. Nessa tendência o professor precisa interligar os conteúdos com experiências concretas dos alunos e auxiliá-los a ultrapassar os limites de suas experiências cotidianas.

A tendência Histórico-crítica, teve como inspiradores Makarenko (Marx); Manacorda, Snyders e no Brasil Dermeval Saviani. Diferente da Pedagogia libertadora, essa tendência é centrada no saber científico historicamente elaborado, o que chamamos de identidade e acervo cultural. A escola possui uma função política que sistematiza o conhecimento, fazendo com que as classes populares participem ativamente e criticamente das lutas sociais, tornando-se assim seres capazes de transformar a sociedade e a si próprios, para isso é necessário o domínio de habilidades e capacidades para interpretar suas experiências e defender os interesses da classe.

Saviani (1987), afirma que a Pedagogia Histórico-Critica, busca articular uma proposta pedagógica, que tem como principal objetivo a transformação da sociedade e não apenas sua manutenção e perpetuação. Nesse sentido a educação é vista como mediadora em meio a prática social que se apresenta como ponto de partida e de chegada do processo de aprendizagem, que deve iniciar com uma problematização. Segundo o autor, a prática pedagógica contribui significativamente para a democratização da sociedade.

Portanto, observa-se que a Tendência Histórico-Critica é a que mais se aproxima do que se espera da educação no século XXI. Uma educação significativa, autônoma, dialética e que tem por finalidade preparar o educando para atuar na sociedade de forma crítica e autônoma.

\section{Resultados e Discussão}

Para alcançar os objetivos propostos buscou-se verificar o conhecimento dos professores sujeitos da pesquisa quanto a tendências pedagógicas que fizeram e fazem parte da educação no Brasil. Para isso realizou-se as observações in loco e de forma online devido ao período de pandemia Covid 19, além de buscar referências em bibliografias e em documentos legais que abordam a temática além analisarmos duas questões que foram aplicadas através do Google formulário. 
A primeira questão do questionário apresenta o seguinte questionamento: Você conhece algumas Tendências Pedagógicas? Se sim, qual delas você acredita se encaixar na sua identidade como professor? Diante do questionamento obtivemos os seguintes padrões de respostas, expressados através da Figura 4.

Figura 4 - Tendências Pedagógicas, com as quais os professores da EECDO se identificam.

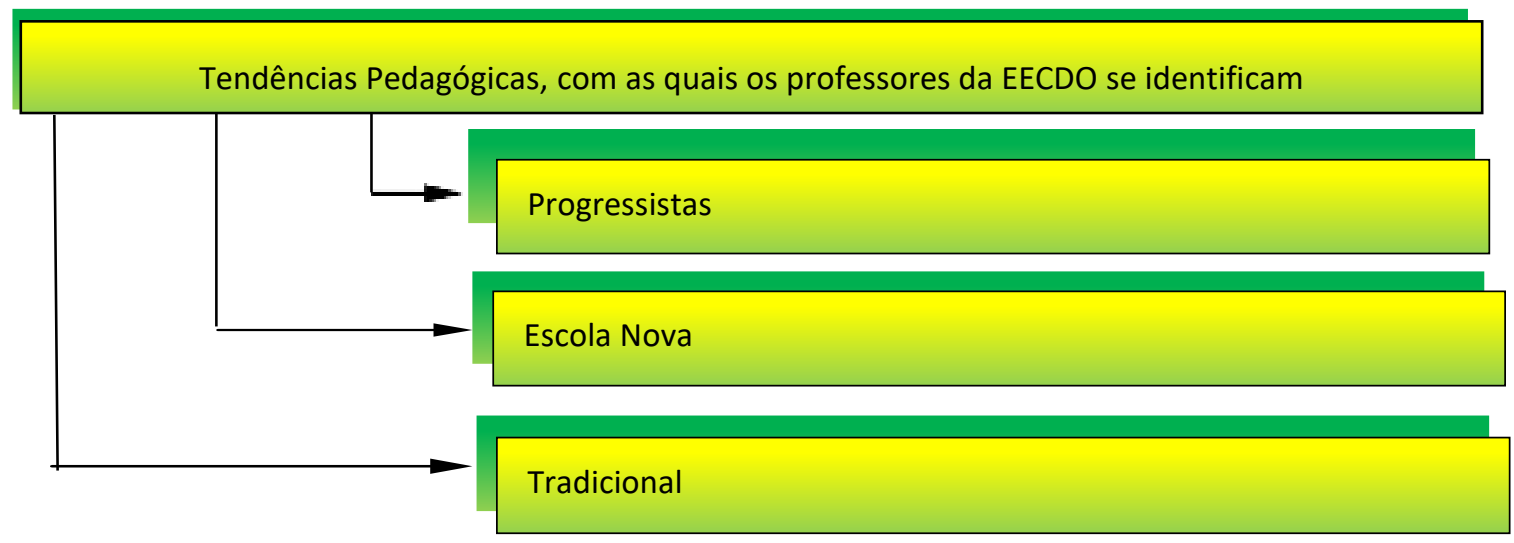

Fonte: Autores (2021).

Entre os padrões especificados acima, um (1) se destacou a tendência progressista. Dos quatorze (14) professores, dez (10) responderam que são adeptos a essa tendência educacional ou citaram suas vertentes. Diante dos resultados, percebe-se que os professores da EECDO buscam dar autonomia ao aluno no processo de aprendizagem, qual o papel do professor frente a essas novas metodologias de ensino. $\mathrm{E}$ isso se constata nas respostas dos sujeitos da pesquisa.

"Conheço a tendência Freireana, na qual o ensino deve servir como ferramenta para a construção do "homem" político. Com esse pensamento me identifico". (P3).

"Eu acredito que me encaixo a uma tendência progressista, pois, penso que a educação precisa inovar, progredir, evoluir, acompanhado o progresso principalmente o tecnológico e digital”. (P7).

[..] "a educação escolar assume o propósito de levar o aluno a aprender e construir conhecimento, considerando as fases do seu desenvolvimento". (P13).

[...] "acredito que enquanto educador estamos em constante mudança, ainda mais no quadro em que a educação se encontra, hoje acredito melhor me encaixar na tendência progressista, no entanto das suas três vertentes tenho dúvida se me encaixo na libertadora ou na histórica - crítica". (P14).

"A tendência pedagógica progressista faz mais sentido, onde o aluno junto com o professor passa a ser o detentor do conhecimento e da sua vida pedagógica não sendo apenas ouvinte, mas também crítico e agente principal do seu saber". (P8).

[...] “acredito que me encaixo melhor nas tendências progressistas". (P9)

É importante o fato de $71,42 \%$ dos professores entenderem que se encaixam em teorias progressistas, pois como se pode observar na apresentação das tendências anteriormente, a ideia do aluno ativo e autônomo está presente em todas elas. $\mathrm{O}$ fato de não se encaixar em uma teoria específica, como colocou o P2, “[...] penso que o professor está sempre buscando, pesquisando para inovar suas aulas, porém não me encontro em uma tendência específica", para Tardif (2014) isto está 
relacionado à formação da identidade do professor, que resulta da fusão de diferentes saberes, provindos de fontes diversas, que são construídos, adquiridos, relacionados e mobilizados pelos professores de acordo com as exigências de sua atividade profissional.

Apenas um (1) professor disse se identificar com os ideais da Escola Nova, que tem o professor como um facilitador do processo de aprendizagem. A Escola nova foi considerada o marco inicial para a tão sonhada educação inovadora, motivada por transformações econômicas, políticas e sociais, tendo como marco principal o "Manifesto dos Pioneiros da Educação" um documento que trazia conceitos e adaptações a serem aplicadas no sistema de ensino no contexto educacional em que encontrava o Brasil naquele momento (Saviani, 2019).

"Tradicional" (P11), o fato de em pleno século XXI com todas essas transformações que vêm ocorrendo no cenário educacional, o professor dizer que se identifica com a tendência tradicional é preocupante. Segundo Bacich e Moran (2018), isso acontece pois o professor tende a reproduzir práticas de professores que influenciaram na formação da identidade antes da docência.

Entretanto, o mais interessante é que durante a observação da aula que aconteceu pelo Google Meet esse professor que relatou ser tradicional, utilizou como metodologia de ensino a aula explicativa dialogada, com um feedback dinâmico e interativo com os alunos, e uma atividade prática como atividade extraclasse. Diante do exposto, fica o seguinte questionamento: será que esse professor é mesmo tradicional? O que ele entende por tradicionalismo? E a formação continuada está abordando de forma correta o conceito de metodologias ativas?

Talvez esse professor não saiba, mas utiliza métodos de aprendizagem que são considerados ativos. Freire (1979) define diálogo como o encontro entre a reflexão e a ação, que é capaz de produzir, transformar e humanizar, tanto educadores como educandos.

Bacich \& Moran (2018) enfatizam que ouvir o aluno, conhecer suas opiniões e o que eles tinham a contar sobre a atividade proposta, seus questionamentos, nos faz perceber que uma aula explicativa dialogada pode se tornar uma metodologia ativa desde que o aluno esteja participando do processo de aprendizagem ativamente. Os Autores ainda acrescentam:

Acreditamos, também, que muito da reprodução de práticas há tempos questionadas deve-se não ao desconhecimento da importância da aprendizagem mediada, mas, em parte, ao conhecimento superficial sobre a mediação e muito mais ao desconhecimento sobre como mediar e o porquê de propiciar a aprendizagem mediada, o que, acreditamos, é um conhecimento construído no fazer pedagógico e na reflexão sobre esse fazer, apoiada em construtos teóricos (Bacich \& Moran, 2018, p.92).

Segundo os autores, isso também acontece devido os cursos de formação inicial estarem defasados. "Fatores como ausência de relação entre a teoria e a prática durante a formação, influência de modelos tradicionais de ensino, experimentados anteriormente ou durante a graduação de docência, e a não desconstrução desses modelos na formação do professor podem justificar o descompasso entre o discurso e a prática” (Bacich \& Moran, 2018, P.91).

A falha na formação inicial também pode justificar o fato de um (1) dos professores não conhecer as tendências pedagógicas, pois este conteúdo está previsto em todas as grades curriculares para licenciaturas, instituído pela Lei de Diretrizes e Bases da Educação Nacional (Brasil, 1996) que estabelece alterações para os cursos de formação de professores, sendo definido um período para efetivação dessas alterações.

Quanto a formação de professores, Pimenta (2005) afirma que o saber docente não é formado apenas da prática, sendo também nutrido pelas teorias da educação, pois dota os sujeitos de variados pontos de vista para uma ação contextualizada, e recontextualizada, oferecendo perspectivas de análise para que os professores compreendam os diversos contextos vivenciados por eles no exercício da profissão. Tardif (2014) enfatiza a importância da formação continuada para a prática 
pedagógica. Para o autor "Tanto em suas bases teóricas quanto em suas consequências práticas, os conhecimentos profissionais são evolutivos e progressivos e necessitam, por conseguinte, de uma formação contínua e continuada. Os profissionais devem, assim, autoformar-se e reciclar-se através de diferentes meios, após seus estudos universitários iniciais" (Tardif, 2014, p. 249).

Ao fazermos um percorrido histórico desde as tendências até o contexto atual observa-se o quão é importante conhecermos as tendências pedagógicas que fizeram e fazem parte da educação no Brasil, pois muitas delas influenciaram e ainda influenciam a prática pedagógica atual.

Considera-se, portanto, que conhecer as tendências pedagógicas contribui de forma significativa para um fazer pedagógico inovador. Comparar essas tendências promove uma reflexão dos pontos positivos e negativos que cada uma possui, faz com que busquemos, como educadores, vestígios de práticas metodológicas anteriores presentes em nosso cotidiano e a partir dessa reflexão possamos romper com alguns laços que não permite a evolução do nosso pensamento pedagógico, inovando o processo de aprendizagem. Carbonell (2002, p.19), define inovação como:

[...] um conjunto de intervenções, decisões e processo, com certo grau de intencionalidade e sistematização, que tratam de modificar atitudes, ideias, culturas, conteúdos, modelos e práticas pedagógicas. E, por sua vez, introduzir, em uma linha renovadora, novos projetos e programas, materiais curriculares, estratégias de ensino-aprendizagem, modelos didáticos e outra forma de organizar e gerir o currículo, a escola a dinâmica da classe.

Portanto compreender as ideias de cada tendência pedagógica faz parte de inovar, buscar novos rumos, novas possibilidades, para tornar o processo de ensino algo prazeroso e contextualizado com a nossa realidade. Cavalcante e Filatro (2018), salientam que a educação precisa inovar, buscar novas alternativas, mas nem tudo que é obsoleto é descartável, e sim devem ser aprimorados de forma a atender às nossas necessidades.

Observa-se que inovar na escola pública não é algo simples, levando em consideração as péssimas condições de trabalho, como a falta de recursos didáticos, principalmente quando falamos em recursos tecnológicos, a escassez de laboratórios, a diversidade de alunos na maioria das vezes oriundos de famílias de classe social menos favorecidas, professor e alunos sem acesso à internet, no entanto, podemos transformar a escola em um espaço interativo, onde o aprendizado é compartilhado entre os seres aprendentes, tornando esse fardo então menos pesado.

Sabemos que as mudanças no sistema de ensino não dependem apenas dos profissionais que estão lotados dentro das unidades educacionais. Serão necessários vastos estudos que estão relacionados aos avanços da qualidade do processo educacional, pois, entendemos que a partir da compreensão de que a educação é uma prática social que se concretiza em um contexto histórico cultural, político e econômico, entrelaçando em seu bojo uma concepção de sujeito, de vida e sociedade, no entanto o professor deve fazer a sua parte, buscar estar sempre se atualizando.

Grande parte das instituições de ensino ainda seguem o modelo pedagógico tradicional, institucionalizado e arraigado nas últimas décadas, com métodos e práticas que não atendem os anseios dos alunos. Pesquisas e estudos revelam o descontentamento e a desmotivação dos alunos com o modelo de ensino tradicional. Camargo \& Daros (2018) citam estudos realizados por Blight (2000), que apresentam a motivação dos alunos com uma aula tradicional e com uma aula ativa, analisando a frequência cardíaca dos alunos.

O Gráfico 1, apresenta a frequência cardíaca de alunos em uma aula na qual o professor utiliza uma metodologia tradicional. Observa-se claramente que os batimentos cardíacos dos alunos decrescem de acordo com o tempo da aula, ou seja, a motivação do aluno vai diminuindo, e quanto maior o tempo da aula menor a motivação. Esse fenômeno acontece quando o aluno tem uma participação passiva, quando ele é apenas um ouvinte. 
Gráfico 1 - Frequência cardíaca dos alunos na aula tradicional.

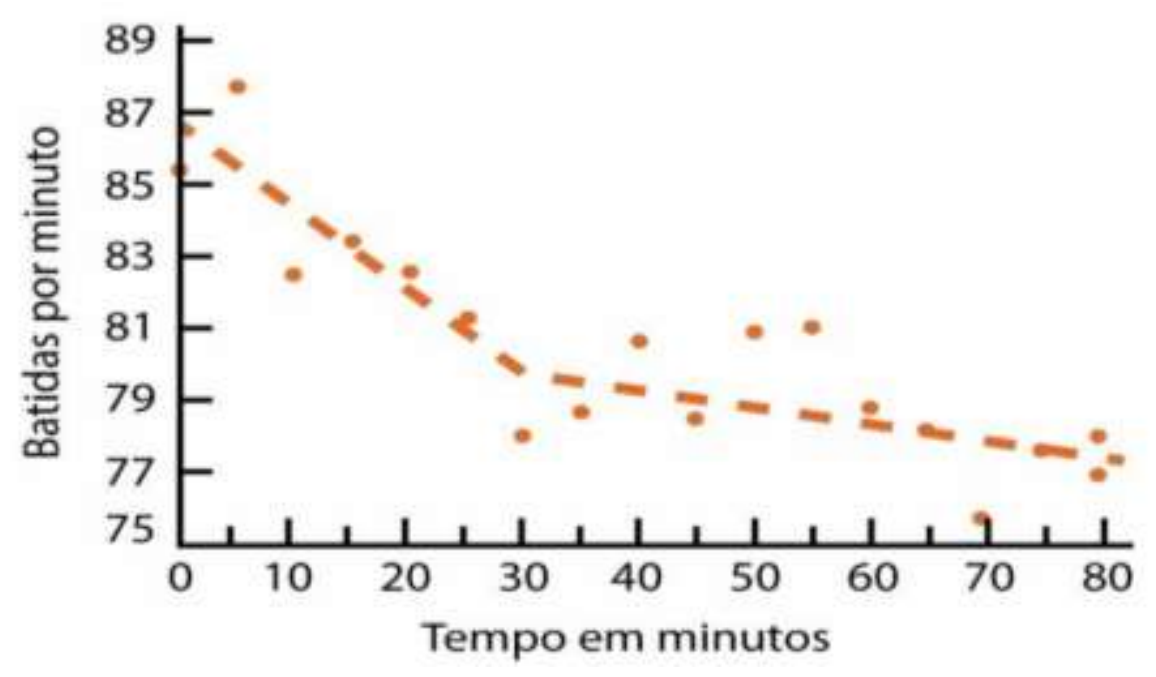

Fonte: Blight (2000, apud, Camargo \& Daros, 2018, p.14).

O Gráfico 2, mostra claramente que os batimentos cardíacos, aumentam quando os estudantes fazem intervenções ou quando há discussões acerca do conteúdo estudado, ou seja, o nível de motivação dos estudantes aumenta pois eles deixam de ser passivos, atuando ativamente no processo de aprendizagem. O momento da palestra reforça essa teoria, nesse momento os batimentos cardíacos diminuem, pois o aluno apenas ouve.

Gráfico 2 - Frequência cardíaca dos alunos em sala de aula.

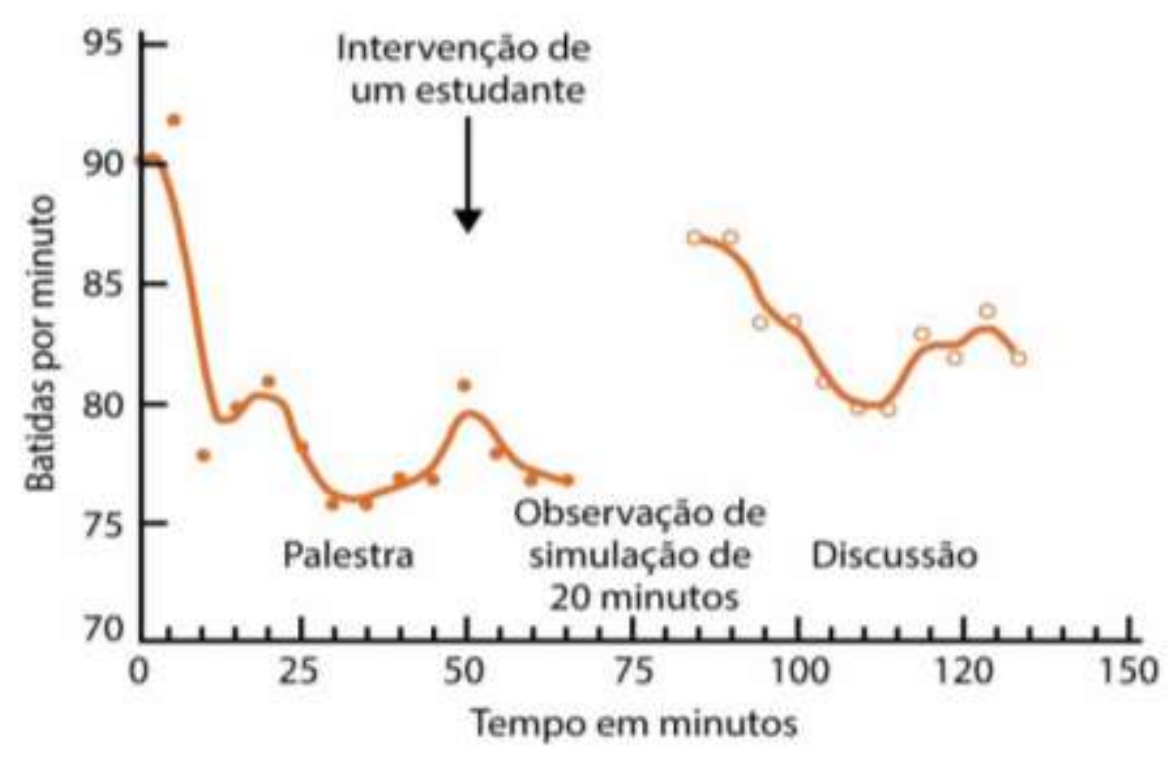

Fonte: Blight (2000, apud, Camargo \& Daros, 2018, p.14).

Camargo \& Daros (2018) também citam os estudos realizados por Dale (1969), onde o autor propõe uma pirâmide de aprendizagem na qual ele apresenta o percentual de retenção de conhecimento de acordo com a metodologia de ensino. Percebe-se que as metodologias na base da pirâmide o nível de aprendizagem é bem maior que em metodologias tradicionais. 
Figura 5 - Pirâmide de aprendizagem.

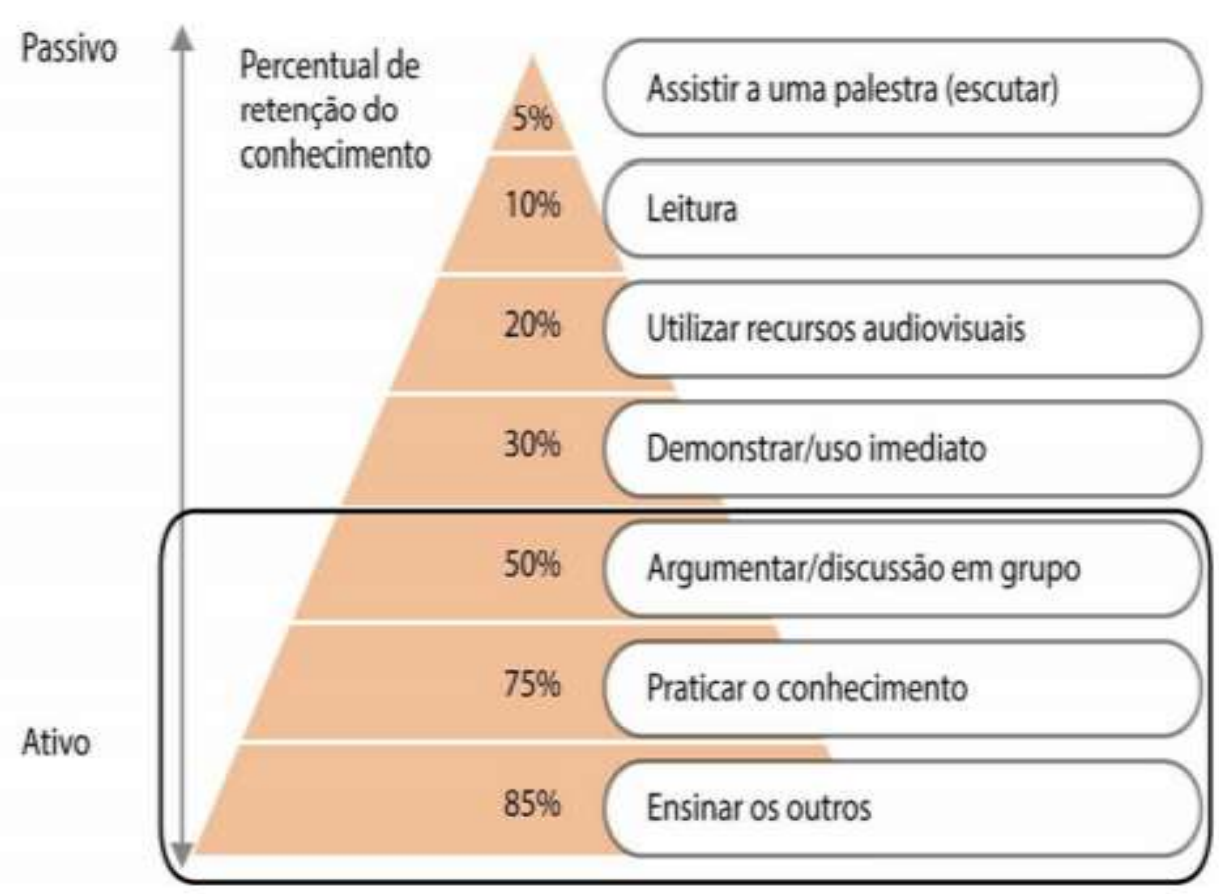

Fonte: baseada em Dale (1969, apud, Camargo \& Daros, 2018, p.17).

Outro estudo interessante citado pelos autores é o estudo realizado por Hake (1998), onde o autor compara os ganhos de aprendizagem com metodologias ativas e com metodologias tradicionais, o estudo foi realizado através da resolução de problemas, em três tipos de instituições: escola, faculdade e universidades. Para melhor compreensão observe a figura abaixo:

Figura 6 - Legenda dos resultados de ganho médio de 6542 alunos norte-americanos através do teste FCI.

\begin{tabular}{|c|c|}
\hline Metodologias ativas & Metodologias Tradicionais \\
\hline Escolas & Escolas \\
\hline Faculdades & Faculdades \\
\hline Universidades & Universidades \\
\hline
\end{tabular}

Fonte: Autores (2021). 
Gráfico 3 - Resultados de ganho médio de 6542 alunos norte-americanos através do teste FCI.

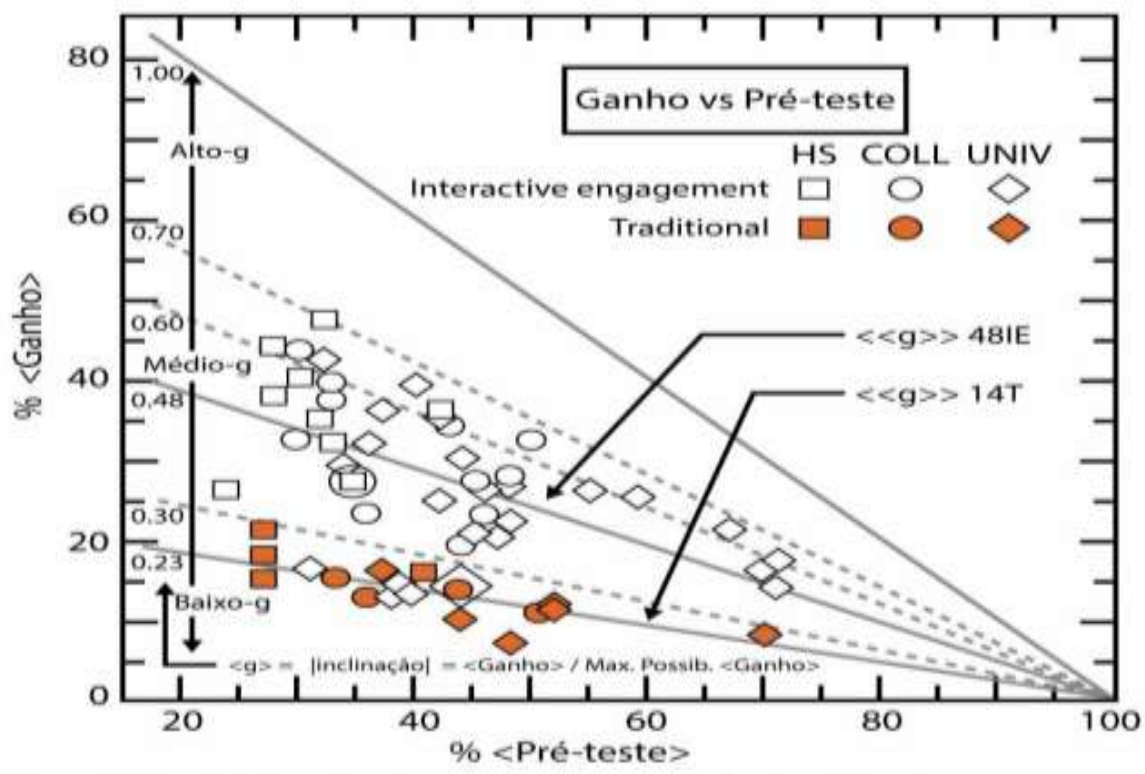

Fonte: Hake (1998, apud, Camargo \& Daros, 2018, p.17).

Como se pode observar, as metodologias ativas causam um grande impacto no ambiente escolar. Elas auxiliam de forma significativa o processo de ensino aprendizagem, mantendo o aluno motivado, isso faz com que índices como indisciplina e evasão diminuam de forma significante.

Em 2000 o MEC elaborou um documento denominado "PROPOSTA DE DIRETRIZES PARA A FORMAÇÃO INICIAL DE PROFESSORES DA EDUCAÇÃO BÁSICA, EM CURSOS DE NÍVEL SUPERIOR” que tem por objetivo direcionar a formação inicial de professores com ênfase nos impactos causados por essa invasão tecnológica.

No mundo contemporâneo, o papel do professor está sendo questionado e redefinido de diversas maneiras. Para isso concorrem as novas concepções sobre a educação, as revisões e atualizações nas teorias de desenvolvimento e aprendizagem, o impacto da tecnologia da informação e das comunicações sobre os processos de ensino e de aprendizagem, suas metodologias, técnicas e materiais de apoio (Brasil, 2000, p.5).

Nesse sentido, Bacich \& Moran (2018), corroboram que a escola caminha a passos lentos em relação à sociedade, os autores enfatizam a necessidade de uma educação instigadora, que estimula o aluno, que provoca, desde a educação infantil até o nível superior. Faz-se necessário grandes investimentos em Políticas Públicas que fomentem a formação inicial e a formação continuada no Brasil.

\section{Conclusão}

A pesquisa mostrou que desde as tendências liberais o método do aluno ativo vem sendo estudado e visto como uma possibilidade inovar a aprendizagem.

Observa-se na pesquisa que alguns professores não conhecem a trajetória da educação brasileira, ou não conhece a definição e as características de algumas tendências pedagógicas. Isso nos leva a questionar a estrutura da grade e a qualidade dos cursos de licenciatura e também a formação continuada, pois uma das temáticas mais presentes na formação atual são as metodologias ativas.

Diante das colocações acima consideradas verifica-se a importância de políticas Públicas que realmente venham promover qualidade na formação inicial e continuada dos professores, além de recursos didáticos que auxiliem o processo de 
aprendizagem. Neste sentido a pesquisa pode auxiliar os cursos de licenciatura, enfatizando a importância de se conhecer os caminhos percorridos pela educação brasileira, pois isso nos leva a refletir sobre a metodologia de ensino que utilizamos em sala de aula.

Reconhece-se a importância de se conhecer a fundo as tendências pedagógicas que fizeram e fazem parte da educação brasileira, pois através desse processo histórico podemos verificar as contribuições que essas metodologias tradicionais podem trazer para um fazer pedagógico significativo e autônomo. Constatou-se durante o estudo bibliográfico que os traços da aprendizagem ativas está presente na educação desde a Escola Nova mesmo que com uma roupagem diferente.

Recomenda-se que a escola insira a temática em sua formação continuada uma vez que nem todos estão familiarizados com a mesma.

Destaca-se que as investigações sobre o tema não se esgotam com esta pesquisa, abrindo possibilidades de novas investigações sobre metodologias ativas e suas contribuições para o processo de aprendizagem.

\section{Referências}

Bacich, L. \& Moran, J. (2018). Metodologias ativas para uma educação inovadora. Ed. Penso.

Brasil. (1996). Lei de Diretrizes e Bases da Educação Nacional. http://www.planalto.gov.br/ccivil_03/leis/19394.htm.

Brasil. (2000). Ministério da Educação. Proposta de diretrizes para a formação inicial de professores da educação básica, em cursos de nível superior. http://portal.mec.gov.br/sesu/arquivos/pdf/ed_basdire.pdf .

Camargo, F. \& DAROS, T. (2018) . A sala de aula inovadora: estratégias pedagógicas para fomentar o aprendizado ativo. Ed. Penso.

Carbonell, J. (2002). A aventura de inovar: a mudança na escola. Ed. Artes Médicas.

Cavalcanti, C. C. \& Filatro, A. (2018). Metodologias Inov-ativas na educação presencial, a distância e corporativa. Ed. Saraiva Educação

Denzin, N. K. \& Lincoln, Y. S. (2006). O planejamento da pesquisa qualitativa. Ed. Penso.

Di Giorgi, C. (1992). Escola nova. 4ed. Ed. Ática.

Freinet, C. (2001). Para uma escola do povo: guia prático para a organização material, técnica e pedagógica da escola popular. Ed. Martins Fontes.

Freire, P. (1987). Pedagogia do oprimido. 17ed. Ed. Paz e Terra.

Gil, A. C. (2008). Métodos e técnicas de pesquisa social. 6ed. Ed. Atlas.

Gonsalves, E. P. (2001). Iniciação à pesquisa científica. Ed. Alinea

Libâneo, J. C. (2006). Democratização da Escola Pública. Ed. Loyola.

Luckezi, C. C. (1994). Filosofia da Educação. Ed. Cortez.

Luzuriaga, L. (1980). História da educação e da pedagogia. 12ed. Ed. Nacional.

Minayo, M. C. S. (2005). Introdução: conceito de avaliação por triangulação de método. In. Minayo, M. C. S., Assis, S. G. \& Souza, E. R. (2005). Avaliação por triangulação de métodos: abordagem de programas sociais. Ed. Fiocruz. p.19-52.

Pimenta, S. G. (2005). Formação de professores: identidade e saberes da docência. In: Pimenta, S. G. et al. (2005). Saberes pedagógicos e atividade docente. 4ed. Ed. Cortez. p.15-34.

Rocha, D. \& Deusdará, B. (2005. Análise de conteúdo e análise do discurso: aproximações e afastamentos na (re) construção de uma trajetória. Alea, dez 2005, v.7, no.2, p.305-322.

Saviani, D. (1987). Escola e Democracia. Ed. Cortez/Autores Associados.

Saviani, D. (2019). História das ideias pedagógicas no Brasil. Ed. Autores Associados.

Tardif, M. (2014). Saberes docentes e formação profissional. Ed. Vozes. 